\title{
En torno de la noción de subjetivación en psicoanálisis: entre dinámica pulsional, identificación y objeto
}

\author{
About the notion of subjectivation in \\ psychoanalysis: between drive dynamic, \\ identification and object
}

Alejandro Bilbao*1

Daniel Jofré*2

El artículo brinda un detenido análisis sobre el concepto de subjetivación en psicoanálisis, evidenciando la relevancia que esta categoría adquiere para comprender el carácter psíquico y relacional de las dinámicas pulsionales supuestas por la teoría psicoanalítica. Sin ser una categoría de análisis trabajada directamente por Freud en sus estudios clínicos o metapsicológicos, la subjetivación puede actuar como una hipótesis derivada del trabajo historizante que las pulsiones inconscientes cumplen en el devenir de la vida psíquica. Junto con especificar el vínculo que guardan nociones tales como: sujeto, pulsión, identificación, objeto y trasferencia, la subjetivación permite comprender de mejor manera la acción clínica realizada por el ejercicio del psicoanalista. El carácter psíquico y relacional puesto en juego por la noción de subjetivación es finalmente ilustrado por medio de un caso clínico.

Palabras claves: Psicoanálisis, metapsicología, pulsión, identificación, objeto

*1,2 Universidad Austral de Chile (Puerto Montt, Chile). 
Travailler un concept, c'est en faire varier l'extension et la compréhension, le généraliser par l'incorporation des traits d'exception, l'exporter hors de sa région d'origine, le prendre comme modèle ou inversement lui chercher un modèle, bref lui conférer progressivement, par des transformations réglées la fonction d'une forme.

(Canguilhem, 2002, p. 206)

\section{Introducción}

El presente artículo se sitúa al interior de las discusiones clínicas y metapsicológicas abiertas en la actualidad por la noción de subjetivación. Ya sea en uno u otro de estos niveles, la subjetivación deviene una categoría de relevancia para pensar los procesos psíquicos que obran en la simbolización de las formaciones inconscientes, permitiendo observar de otro modo a los distintos dinamismos, conflictos e impasses presentes en el devenir de la vida psíquica (Cahn, 2004; Lauru, 2016; Le Poulichet, 2004; Pirard, 2013).

Una consideración preliminar referida a la problemática de la subjetivación en los textos freudianos, sumerge en una cierta orfandad respecto de las referencias elaboradas a este propósito. Sin embargo, si la noción de subjetivación no es trabajada de un modo explícito por parte de Freud, el cúmulo de las hipótesis referidas a la vida pulsional la supone de un modo importante. Dar lugar a esta noción al interior de los textos freudianos, implica la generación de un cierto número de interrogantes, que conllevan revisiones metapsicológicas importantes en lo relativo a dos aspectos: a). los modos de organización de los procesos inconscientes; b) la relación que estos procesos mantienen con la categoría de sujeto, de identificación y de objeto. Un primer 


\section{ARTIGOS}

tiempo del artículo, busca tornar explícitas las correspondencias entre estos dos elementos, considerando particularmente las elaboraciones freudianas relativas a la vida pulsional. Son estas elaboraciones las que brindan el soporte conceptual necesario para considerar que, entre la organización de los procesos inconscientes y la idea de sujeto, se erige un modo preciso de comprender el devenir de lo subjetivo. Sometida a ciertos cambios por los requerimientos conceptuales que emergieron durante el trascurso de su elaboración conceptual, la teoría de los agentes pulsionales es un vasto principio explicativo de la progresión de la vida psíquica en el tiempo, permitiendo observar la conformación de sus dinamismos e impasses.

Las "sumas de esfuerzo" y de "trabajo asociativo" que la existencia de las reclamaciones pulsionales comprende para la vida psíquica, constituyen los primeros elementos nosológicos que conducen a Freud a teorizar las diferencias entre las neuropsicosis de defensa y las neurosis actuales. Particularmente en el caso de las neuropsicosis de defensa, los alcances de estas aproximaciones conducirán a la suposición de grupos psíquicos separados, organizados por capas de estratificación y registro. Mas tardíamente, esta concepción del trabajo pulsional contribuirá a la edificación de las tesis relativas a la fantasía, a observar su papel preponderante en la organización de las hipótesis referidas al narcisismo. El periodo de las tesis de 1914 sobre el narcisismo, conducirá a que la vida pulsional sea vinculada a los procedimientos psíquicos actuantes en el duelo y la melancolía. A su vez, la problemática del duelo abrirá un estilo de reflexión sobre la identificación y el rol del objeto en el devenir de lo subjetivo. Construidas de un modo progresivo, estas tesis relativas al devenir de lo psíquico, son el resultado del baluarte conceptual que la teoría pulsional constituye para el freudismo, conformando la antesala del concepto de subjetivación. En Freud, la problemática de la subjetivación permanece supeditada de un modo expreso al trabajo pulsional, siendo una hipótesis admisible solo de un modo subrogado, mediada por la serie extensa de otros fenómenos vinculados a los procesos inconscientes. Este es el escenario que Freud define para un vocablo que adquirirá mas tardíamente, relevantes extensiones al interior de la teoría psicoanalítica (Rousillon, 2012; Canh, 2004; Richard, 2001; Green, 2015).

Un segundo tiempo del artículo, aborda el valor conceptual y heurístico de la noción de pulsión, para profundizar posteriormente por medio de esta valorización, en la genealogía del concepto de subjetivación. Para trazar el itinerario de esta genealogía, se toman en consideración dos aspectos. En primer lugar, los procedimientos inconscientes definidos por Freud para 
pensar la mecánica pulsional y su relación con el accionar representativo. En segundo lugar, se profundiza en el vínculo que supone la argumentación de la vida pulsional y el fenómeno del devenir-sujeto, conduciendo estas hipótesis al problema de la inmutabilidad del registro pulsional y su relación con los agentes representantes. Estas observaciones se extienden al examen de una pequeña viñeta clínica, donde el concepto de subjetivación puede ser apreciado en toda la riqueza que presta para pensar los enclaves e impasses del devenir-sujeto. Como puede ser observado, la relevancia de esta noción fuerza un trabajo de revisión de sus fundamentos metapsicológicos, así como sus posibles modos de vinculación a problemáticas clínicas contemporáneas.

\section{I - Freud, mecánica pulsional y accionar representativo}

Las secuencias de desenvolvimiento de la pulsión (fuente, meta, fin y objeto), ordenan exigencias de transformación y diferenciación que suponen medidas de trabajo para lo psíquico, introduciendo los requerimientos de la representación y del pensar simbólico (Vorstellung). El que estos procedimientos de representación operen de acuerdo a criterios introducidos por la variable pulsional, recuerda que estas acciones de tramitación actúan como traducciones posibles de las exigencias internas del organismo. Entre mecánica pulsional y accionar representativo, la idea de devenir-sujeto incorpora las hipótesis relativas a la existencia de una energía en libre movimiento y otra ligada, dando lugar a los denominados procesos primarios y secundarios. Estos procesos describen un doble ámbito de discernimiento. En primer lugar, actúan de manera intra-sistémica, afectando a las modalidades de funcionamiento de los sistemas de representación y registro inconsciente. Destaca así el llamado factor económico, cuantitativo de la vida anímica, para demostrar que estas magnitudes pueden desencadenar desbordamientos afectivos que al ser vinculadas a otros sistemas de representación, hacen florecer la idea de conflicto y de oposición entre representaciones. En lo referido a las primeras intelecciones relativas a la libre conectividad y asociación de las huellas mnémicas traumáticas de la histeria, estos procesos dan cuenta de la representación de la vida anímica dividida por sistemas de funcionamiento autónomos, y con la capacidad de incidir en la organización de otros (Freud, 1896/1986c). Este segundo aspecto, denominado inter-sistémico, dará lugar al entendimiento de las formas de manifestación de los múltiples síntomas histéricos, y al procesamiento interno que la organización mental podrá 


\section{ARTIGOS}

establecer frente al dolor y el sufrimiento (Freud, 1893-1895/1986a). Esta elaboración que expresa las relaciones y continuidades entre distintos sistemas mnémicos, connota decididamente una idea temprana de pulsión, visible en el entendimiento que Freud destina a los estímulos internos que actúan de un modo permanente en el organismo. Aun si Freud no habla de pulsión en los textos correspondientes a la última década del siglo XIX, las reclamaciones a las cuales se ve sometido el individuo como consecuencia del accionar de presiones internas, corresponde de manera preliminar al baluarte conceptual que Freud verá posteriormente erigirse en torno del concepto. Para este primer periodo de indagaciones, si el concepto de pulsión aparece tácitamente expuesto en las modalidades que el organismo establece para dar tramitación a las tensiones internas, parecido estatuto es el que recibe la categoría de objeto. Inicialmente para Freud, el objeto puede ser pensado en un triple registro. En primer lugar, como un agente expresivo de las efracciones psíquicas acontecidas como consecuencias de las experiencias traumáticas. En segundo lugar, como la entidad que brinda las posibilidades del signo y de la representación (en la aceptación de una posición más arcaica y pretérita del objeto). En tercer lugar, el objeto puede ser considerado como un vector que permite introducir el fenómeno de la identificación para pensar los objetos pulsionales como otros pulsionales. Este tercer aspecto evidencia que las transformaciones que son propias a la vida pulsional, no conciernen exclusivamente a los dinamismos que se manifiestan en un sistema mnémico en particular, o en las relaciones que este sistema entabla con otras organizaciones de registro. La hipótesis del otro pulsional destaca la dimensión subjetivante del objeto, su rol activo en los procedimientos de devenir-sujeto. Tempranamente, para Freud, el lugar del objeto delimitará una inquietud relativa al semejante en la construcción del psiquismo, distinguible en los postulados expuestos en el "Proyecto de psicología para neurólogos" (1950[1895]/1986g). Por medio del fenómeno del desamparo (hilflosigkei) y del complejo del prójimo (Nebenmensch), Freud aborda en 1895, la importancia de la faceta relacional del objeto. Un cometido similar acompaña los propósitos que se dirigen respecto de las neurosis de angustia y de la neurastenia (1895[1894]/1986b) que, definidas como neurosis actuales, expresan un modo de descarga que no procede de acuerdo a la lógica del "buen momento" ni del lugar "más adecuado". En ambas neurosis se observan procedimientos de descarga de excitaciones en ausencia del objeto (o en el objeto). En estos estudios, Freud destaca la amenaza que los procedimientos de descarga generan para el aparato anímico cuando la satisfacción se produce en ausencia del objeto. 
Ya sea de las elaboraciones destinadas a pensar las neurosis actuales, o de los desarrollos referidos al modelo del deseo que se desprende de la vivencia de satisfacción, Freud evoca las condiciones traumatizantes del ejercicio de una sexualidad sin objeto (patente en las ideas que trabaja a propósito del coitus interruptus y del onanismo). Frente a estas intelecciones, se podría confundir el objeto de la pulsión con el objeto externo, generando ciertos equívocos en la relevancia que debe ser acordada al objeto en la trayectoria "subjetivante" que cumple la pulsión. En 1920, en el texto que Freud consagra al estudio de la identificación y los ideales del sujeto, el objeto es considerado en el plano del ideal del yo; es un objeto interno trasferido sobre otro sujeto tomado como objeto de la pulsión. Que ese objeto obedezca igualmente a los requerimientos pulsionales actuantes en el sujeto que es agente de la pulsión, es una idea que Freud concibe en el mismo texto de 1920, al momento de referirse al lugar del semejante como "objeto" o "sujeto" para el yo. Se trata de un punto en la teorización de Freud donde se radicaliza la función subjetivante de la pulsión. El objeto puede ser tomado como una forma "de hacer" pero también "de ser". La identificación destaca este doble aspecto del objeto, de un objeto que puede ser considerado otro sujeto. Al respecto Freud señala:

La diferencia depende entonces, de que la ligazón recaiga en el sujeto o en el objeto del yo. La primera ligazón ya es posible, por tanto, antes de toda elección sexual de objeto. En lo metapsicológico es más difícil presentar estas diferencias gráficamente. Solo se discierne que la identificación aspira a configurar el yo propio a semejanza de otro, tomado como "modelo" (Freud, 1921/1986f, p. 100)

Que las ligazones recaigan sobre un sujeto u objeto para el yo, muestra que ese otro se encuentra en el origen de los procedimientos de constitución de lo subjetivo, pudiendo actuar en la conformación de los ideales y de las identificaciones más tempranas. El yo propio conformado a semejanza de un otro que es instituido en el lugar de modelo. Dos formas de ligazón que pueden recaer sobre las formas de hacer (objeto) o de ser del yo (sujeto). El carácter de este pasaje delimita una operación estructural que puede ser llamada función-sujeto, que ubicada como una parte activa de los procedimientos de la identificación ("sujeto para el yo") asienta una forma de organización mental frente al objeto. El pasaje citado muestra que las ligazones pueden actuar por medio de un cruce de lapsos, frente a un otro que puede ser tomado como el motivo inaugural de las incorporaciones identificatorias, un objeto interno que otorga orden para las reclamaciones 


\section{ARTIGOS}

pulsionales, pero que puede convertirse según ese mismo modelo de incorporaciones, en objeto de la pulsión. Freud lo destaca de este modo al señalar:

Puede ocurrir después que el complejo de Edipo experimente una inversión, que se tome por objeto al padre en una actitud femenina, un objeto del cual las pulsiones sexuales directas esperan su satisfacción; en tal caso, la identificación con el padre se convierte en la precursora de la ligazón de objeto que recae sobre él. (1921/1986f, p. 100)

Este movimiento actuante de la pulsión que destaca de su objeto la dimensión de otro sujeto, puede ser igualmente hallado en las acotaciones de 1915, donde la categoría de sujeto es nuevamente considerada.

En cuanto al par de opuestos sadismo-masoquismo, el proceso puede presentarse del siguiente modo:

El sadismo consiste en una acción violenta, en una afirmación de poder dirigida a otra persona como objeto. Este objeto es resignado y sustituido por la persona propia. Con la vuelta hacia la persona propia se ha consumado también la mudanza de la meta pulsional activa en una pasiva. Se busca de nuevo como objeto una persona ajena, que, a consecuencia de la mudanza sobrevenida en la meta, tiene que tomar sobre sí el papel de sujeto. (1915/1986d, p. 123; destacado nuestro)

Las mudanzas de las metas pulsionales, evidencian que la suposición de la "función-sujeto" queda situada en el plano de las trasformaciones que son propias a la pulsión, la cual asigna lugares sin tomar en cuenta los desplazamientos imaginarios que se sitúan en el yo de ambos sujetos. Estos tiempos subjetivantes pueden ser equivalentes de los registros de oposición que J. Lacan elabora para distinguir el campo del Otro de los pequeños objetos imaginarios. Estas breves líneas de 1915, muestran que lo que es relevante para el dominio de las representaciones psíquicas internas, también lo es para el encuentro y los mensajes que son dirigidos al otro.

Ahora bien, no puede pensarse que estos alcances metapsicológicos se encuentren desvinculados de los problemas que atañen al ejercicio de la cura psicoanalítica. El proceder de la terapia psicoanalítica concibe el funcionamiento trasferencial de acuerdo a un número importante de estas premisas. Entonces, ¿cómo concebir el funcionamiento pulsional bajo transferencia admitiendo que la pulsión pueda dirigirse a un objeto considerado como otro sujeto? El desarrollo de los fenómenos trasferenciales evidencia una concepción altamente subjetivante y transitiva de la vida 
pulsional, siendo visible en la búsqueda de reconocimiento que es dirigida al objeto. Junto a las tres vías que Freud construye para comprender la acción representativa de la pulsión (representaciones de palabra, representaciones de cosa, valor transitivo del afecto), se ordenan también las acciones de mensaje que yacen en sus manifestaciones (mensajes representados, re-actualizados y representados en el vinculo transferencial). En todas y cada una de estas acciones representativas de la pulsión, se pueden hallar mensajes dirigidos a un objeto que es igualmente un otro sujeto (de valor subjetivo e intersubjetivo).

En Freud, la vida pulsional destaca las medidas y esfuerzos de representación que obran en la apropiación de lo subjetivo, indicando que las acciones de devenir-sujeto se entrelazan en un dominio que es potestad del sujeto y del objeto. El concepto de pulsión puede ahora legitimar el carácter de ciertas interrogaciones relativas a la noción de subjetivación: ¿Cómo puede la noción de subjetivación autorizar la idea de un tránsito subjetivo, de un devenir-sujeto? ¿Qué es en el fondo lo que logra ser representado y subjetivado en este devenir?

Puede observarse que la problemática de la subjetivación propicia una atención conceptual importante en torno de la vida pulsional, delimitándola en dos ámbitos de reflexión. En primer lugar, se encuentran las relaciones que los requerimientos pulsionales entablan con la vida de representaciones; la pulsión entendida como una "inclinación inicial" que da por resultado una "condición" para la vida de representación. La fórmula freudiana relativa a la substitución de los espacios psíquicos entre las formaciones del ello y del yo (Wo es war soll ich werden), delimita el tono pre-subjetivo actuante en estas operaciones, mostrando el trabajo subjetivante que la pulsión ejerce por medio de sus movimientos y transformaciones. Que el yo deba advenir en un trabajo de figuración y simbolización "allí donde Ello era", concierne desde un inicio al trabajo subjetal que la pulsión inscribe por medio de sus diversas formas de funcionamiento. En segundo lugar, la pulsión surge de la relación que es mantenida con los agentes representantes, delegados de las exigencias que emanan del organismo. En su vínculo con los agentes representantes, la pulsión puede brindar una visualización de conjunto respecto de los mecanismos implicados en las formas de apropiación de lo subjetivo inconsciente. Esta posición de la pulsión entendida como la condición de existencia de un empuje pre-subjetivo", no es la formulación de una metafísica del devenir-sujeto, derivada de las solas observaciones relativas a las trasformaciones pulsionales. Por otra parte, el trabajo ejercido por las 


\section{ARTIGOS}

transformaciones pulsionales inconscientes que suponen la participación de la faceta simbólica y representacional, no puede ser concebido como un fenómeno que optimice en el tiempo las reacciones que el organismo organiza frente a estímulos internos o externos. El obrar de este trabajo no constituye ningún modelo de síntesis de procedimientos que deberían optimizar y aun inhibir las acciones de falso reconocimiento que operan en los momentos arcaicos de la vida mental (comprendiendo sus modalidades de satisfacción alucinatorias), delimitando frente a las exigencias que son formuladas por la vida, de nuevas facetas cognitivas elaboradas como consecuencia de la evolución de la organización mental (en su relación con el medio y los objetos). La pulsión integra en Freud, una dimensión distinta, que por su accionar recursivo, compone la variable del devenir subjetivo al interior de una temporalidad que es siempre anterior, en los modos que posee de re-editar los conflictos del pasado arcaico. La vida psíquica capturada por los fragmentos de un tiempo anterior antinómico a toda forma de síntesis. Por medio de esta síntesis inacabada, la pulsión comporta en términos metapsicológicos un doble tiempo de apertura para lo anímico. El primero de estos tiempos es el de la fijación, el segundo, la imposibilidad inaugural de representación. La descripción de estos tiempos es expuesta por Freud en 1915.

Pues bien; tenemos razones para suponer una represión primordial, una primera fase de la represión que consiste en que la agencia representante (Representanz) psíquica (agencia representante-representación) de la pulsión se le deniega la admisión en lo consciente. Así se establece una fijación; a partir de ese momento la agencia representante en cuestión permanece inmutable y la pulsión sigue ligada a ella. Esto acontece a consecuencia de las propiedades de los procesos inconscientes, que hemos de considerar después. (1915/1986e, p. 143)

En este pasaje, Freud ordena a partir de la idea de fijación, el vínculo entre las agencias representantes y la pulsión, declarando la ausencia de una valencia de representación para la represión originaria. Sin embargo, la ausencia de valorización no evita el entendimiento de la suma de trabajo realizado, pues el lazo generado entre la pulsión y el mecanismo de la fijación, da lugar a la permanencia de un tipo de vínculo considerado inmutable. La pulsión permanecerá ligada a una imposibilidad de representación que es al mismo tiempo, la condición de la presencia de un empuje pre-subjetivo. Impotencia de la función representativa, pero que, en relación a las tramitaciones posteriores, adviene como la función facilitadora del ejercicio representativo y verbal. La teoría del pensar onírico será una 
de esas variantes, presentando a la función simbólica del sueño como una resistencia ya elaborada y atravesada por la represión. Lo mismo se observará en las formaciones defensivas originadas por la "represión propiamente dicha", actuante en síntomas y producciones fallidas.

La idea de fijación como la de inacabamiento representativo, estipulan modos de disposición psíquica frente a lo pulsional, asociando la condición pre-subjetiva a las modalidades de representación de lo inconsciente. La problemática de la pulsión evidencia para las indagaciones de 1915, que Freud no inquiere en la represión bajo el afán de discernir de un modo general en las modalidades de institución de los mecanismos defensivos. Antes de esta preocupación, prima el interés por hallar los principios rectores de un modelo de conjunto para la vida pulsional. Un modelo que pueda abarcar las relaciones que el psiquismo mantiene con el sufrir, con el dolor, con el pensar onírico, con lo arcaico y con el semejante. Por medio de estas distintas variantes, la subjetivación de la vida psíquica expresa el problema del devenir-sujeto.

Si uno de los aspectos más esenciales del concepto de subjetivación dice relación con la realidad subjetivante que la pulsión construye por medio de la acción de sus mecanismos y trasformaciones, cabe mencionar que estos 26 alcances se tornan visibles gracias a la atención que el psicoanálisis presta a la idea de Fijación e inacabamiento representativo. El trabajo elaborado por Freud en 1915 a propósito de la represión originaria, nos inclinaba a analizar inicialmente dos tiempos que se desprendían de sus intelecciones. La fijación permite elaborar el desarrollo de un tiempo primero, lapso de institución de la impotencia del significante, pero posibilidad de apertura de las series de representación solicitadas posteriormente por la vida pulsional. Estos dos tiempos de hacer con la pulsión y frente a la pulsión, es también la traducción del relevo de los agentes representantes, para de ese modo operar sobre un real hecho diferencia. Son estas diferencias las que permiten el transitar de la concatenación significante, bajo el efecto de un transcurrir que acontece para el yo, según los momentos de su propia organización. El registro de la imagen presta de esta manera una pregnancia importante para las posiciones que el yo entabla frente al objeto, para las formas que posee de organizar el encuentro con su doble i(a).

Aun si la diferencia significante introduce un orden sobre la constelación de imágenes que se vuelven constitutivas para el yo, ellas son irreductibles al solo ejercicio de las agencias representantes, pues la diferencia no actúa solo desde la organización de la propia cadena significante, sino desde lo real (Lacan, 1964/1992). Los pasajes extraídos del texto de 1915, muestran 


\section{ARTIGOS}

que quien se erige en posición de agente de la pulsión, puede mudarse en objeto de ésta según el modo de proceder de la relación del sujeto al Otro. De este modo, la función-sujeto, no podría ser percibida en las mudanzas que son erguidas por las posiciones imaginarias que el yo del sujeto establece a partir del circuito construido por la pulsión, pues el efecto estructural de organización de la función-sujeto, es co-sustantivo a la propia pulsión, un efecto de "disparidad subjetiva".

Disparidad no es un término que haya elegido fácilmente. Este destaca una disimetría entre los sujetos. Es insurgente desde un principio a la idea de que la intersubjetividad pueda ella sola proveer el marco en el cual se inscribe el fenómeno. (Lacan, 1960-1961/1991, p. 11)

\section{II - Respecto del valor conceptual y heurístico de la noción de subjetivación. La dimensión del devenir-sujeto vista desde el objeto}

Hemos tomado a la problemática de la subjetivación destacando su valor de concepto, la situamos en relación al campo de desempeño de otros enunciados, observando el grado de sus formalizaciones, y la legitimidad teórica de sus proposiciones. Por medio de la valorización epistemológica concedida al obrar de los conceptos freudianos, ha sido posible observar en la noción de pulsión una labor de lectura crítica para el problema en cuestión. Las tesis relativas a la vida pulsional permiten observar la problemática de la subjetivación asociada a los problemas clínicos y metapsicológicos conformados por la dimensión de lo intersubjetivo. Mediada por la noción de subjetivación, la dimensión intersubjetiva abre una revisión importante relativa al estatuto del objeto en psicoanálisis y su accionar en el devenirsujeto. El entendimiento del aspecto subjetal e intersubjetivo permitido por la idea de pulsión, torna visible que la comprensión de los tiempos y modos de organización del yo no se cumplen en una referencia directa al otro. Al considerar en esta referencia al semejante a la variable pulsional, es justamente el status de ese vínculo el que se pone en cuestión. Motivo de amor, de explotación, pero también de reconocimiento y de reciprocidad, este otro adviene en las distintas trasformaciones que la pulsión produce en el ámbito de sus objetos y agentes. La pulsión define para Freud el tipo de vínculo que se organiza con ese otro, estructurando e interrogando los lugares que son asignados en esa relación. En la atención prestada a la noción de pulsión, es una hipótesis relativa al inconsciente la que es nuevamente revisada, 
permitiendo discernir la congruencia que la noción de subjetivación expresa cuando esta es expuesta frente a los postulados de la metapsicología freudiana.

El modelo pulsional expuesto por Freud, conduce a considerar que la problemática de la subjetivación es otro modo de nombrar las relaciones que se establecen entre las reclamaciones pulsionales y la faz representativa del lenguaje y la simbolización. Pudiendo igualmente figurar las modalidades heterogéneas de existencia de los objetos pulsionales. Mediada por los postulados de la vida pulsional, la subjetivación muestra que en los orígenes de la vida psíquica, el sujeto fue objeto antes de devenir sujeto. El objeto surge como una entidad capaz de organizar el nacimiento de todos los motivos morales, tornando visible que el camino del si-mismo (en todo caso del ello al yo), no es un dato inmediato de la experiencia. Las formas de apropiación y figuración simbólica, incorporan tempranamente el trazo aportado por el objeto, de ese objeto que es también; otro sujeto. Reflejo de sí y de quien se depende en la estructuración del deseo. La expresión de la fuerza de un trabajo psíquico exigido para figurar el estado de pasividad de esta posición primera, es reflejo del carácter relacional del objeto. Tempranamente, Freud advierte que esta posición de objeto del lactante es reflejo de su incapacidad para conducir acciones específicas, estas solo sobrevienen mediante el auxilio ajeno. Es por medio de la descarga de las alteraciones internas que un individuo experimentado advierte el estado de tensión del niño. Esta vía de descarga cobra así la función secundaria, importante en extremo para la génesis del entendimiento (Verstangung).

Las relaciones intersubjetivas del sujeto al otro no se pueden comprender en el abandono de la hipótesis pulsional, pues ella reúne toda la originalidad de los postulados psicoanalíticos. Se trata de un otro admitido en la presencia de un mensaje subjetivo, que lo captura en una disparidad de posiciones, pero contemplándolo como objeto (de allí el tono intersubjetivo). El alcance mensajero de la pulsión solo guarda ese sentido cuando el mensaje va hacia el objeto, se desarrolla con el objeto y se produce en él. Algunas cuestiones de significativa incidencia para la clínica y el funcionamiento transferencial se desprenden del vínculo de este mensaje subjetivo.

\section{Viñeta clínica}

Juan es hijo de un matrimonio tempranamente disuelto, los motivos de su crianza lo llevaron a un distanciamiento forzado con su padre, a quien verá 


\section{ARTIGOS}

de manera esporádica. Las reclamaciones por su partida se hacen sentir con conductas violentas y agresivas, dirigidas en principio a su madre, y luego a hermanos y familiares. Situación que se acentuará con el advenimiento de la adolescencia, periodo en el cual surge una restricción importante de sus vínculos sociales, acompañado del consumo de substancias tóxicas, de alcohol $\mathrm{y}$ de claras conductas de riesgo. El contexto del vinculo transferencial es difícil desde un inicio, manifestando su incredulidad respecto de la eficacia de la tarea emprendida. Soporta mal mis ausencias del País por periodos cortos, interpretándolas como verdaderos abandonos. El curso del análisis revela posteriormente, que estas dificultades, se encontraban asociadas a las partidas de su padre al extranjero, ya que se desempeñaba para aquel entonces como marino mercante. Su padre se volverá por ello, prácticamente inalcanzable, sin poder disponer de los tiempos y espacios que el paciente estima necesarios para poder establecer una relación filial. Las conversaciones serán siempre al pasar de un puerto a otro, en pocos minutos, sin demasiada atención a los requerimientos afectivos de Juan. Ciertos momentos del análisis se desarrollan en un plano similar, haciéndome saber que él debe ser para mí el paciente menos importante, que mi escucha se encuentra supeditada al pago de las sesiones, que debo ser un analista muy ocupado y que, en razón de ello, debo prestarle escasa o nula importancia a todo cuanto me relata en sesión. Adicta a las benzodiacepinas, su madre desestima sus reclamaciones, siempre dormida y distante de los "buenos momentos" que el paciente desearía tener con ella, aun si solo fuera para sostener un dialogo trivial. El diván genera angustia, en un principio no desea recostarse, el diálogo es fluido y sostenido mientras se inicia la sesión, luego el tono cambia y el silencio se acentúa. La disposición agresiva y hostil al análisis se hace patente en su actitud frente a mis señalamientos, evidenciados en movimientos faciales y golpes que realiza en la pared contigua al diván.

Se podría decir que la palabra es tomada por Juan en el sentido de un simple arrojo, en desmedro de su función asociativa y reflexiva. Un uso de la función de la palabra organizada al modo de un intento de recuperación de un narcisismo perdido, tentativa de evitar el surgimiento de fantasías de aniquilación de amplio alcance para su vida psíquica. El uso de la interpretación es igualmente desalojado durante el curso de numerosas sesiones, bajo un insistente "no puede ser de ese modo", como una manera de desestimar aquello que potencialmente podría ingresar por el mismo camino del rechazo de anteriores representaciones. El trabajo interpretativo debe entonces volverse prudente, permaneciendo atento a las producciones inconscientes de Juan y su tolerancia para aceptar un material rechazado. Cada vez que realizo una 
intervención, la postura gestual de Juan es de una verdadera incomodidad, acomodando en distintas direcciones su cuerpo, o bien dando pequeños golpes a la pared cercana al diván. Esta actitud puede llegar a hacer crujir los dedos con cierta violencia, o a ponerlos sobre su boca de manera rígida.

A pesar de las grandes dificultades que Juan evidencia con las partes escindidas de su interior, ya sea por medio de las representaciones verbales, o por las manifestaciones afectivas visibles dadas en el descontrol pulsional, o simplemente por el tono gestual de algunas de sus reacciones, las solicitudes de mensaje son evidentes. La relación al objeto se desarrolla por cosas que pueden introducirse por el orificio de la boca, debiendo por ello detenérselas. Tomada la trasferencia como modalidad de reactualización, presentación y representación del objeto, Juan comunica el estado de una organización fantasmática primitiva, aun si no hay para ella expresión verbal directa. Esa parte escindida y reprimida se manifiesta en el tono de un mensaje dirigido por sus acciones corporales y gestuales. El plano de las representaciones afectivas también es efecto de una acción mensajera, en las molestias que expresa con sus golpes a la pared y el tono verbal hostil frente a mis intervenciones. Estos diversos planos de representación para las exigencias pulsionales (afectivo, gestual y verbal) destacan el momento intersubjetivo de la experiencia del análisis, dirigido por la "disparidad subjetiva" de la pulsión, tornando visible la relevancia de la problemática de la intersubjetividad para pensar el lugar que es asignado a la subjetivación. Tal y como se mostrara, el vínculo de Juan con su padre se torna inaprehensible desde diversos ángulos y perspectivas. Cuando Juan intenta iniciar un diálogo, su padre ya no está, ocupado en otras tareas y asuntos, tornándose en un objeto prácticamente inalcanzable. La toma en cuenta del factor pulsional, nos muestra a la pulsión en el estado de un impulso quebradizo, descompuesto, retirado y vuelto sobre sí. La vida es la que se torna restrictiva en este movimiento de retiro de la pulsión, y que tanta fuerza tomará con el advenimiento de la adolescencia de Juan. El objeto no es utilizable, la pulsión se detiene en un trabajo de subjetivación donde el objeto no participa. Y donde según los ejemplos dados, la vida pulsional y afectiva no puede ser integrada y menos aún simbolizada.

La preocupación que este caso amerita por las formas de representación de la pulsión (donde están presentes los elementos verbales, afectivos y gestuales), o por las variaciones particulares que en la vida de Juan introduce la relación al objeto, evidencian el rol destacado que la intersubjetividad y la subjetivación cumplen en el ejercicio de devenir-sujeto. 


\section{ARTIGOS}

Este caso es sin duda, ilustrativo de las tensiones del trabajo de subjetivación que opera en la adolescencia. El trabajo adolescente requiere del establecimiento del sujeto en un entorno en donde el partenaire sexual y el grupo de pares, adquieren la dimensión y la potencia que las figuras parentales tuvieron durante la infancia. Sin embargo, este proceso no está exento de dificultades, requiere en primer lugar como señala Serge Leclaire (1975) "hacer desaparecer al niño", y con él, a los apuntalamientos y objetos constituyentes del mundo infantil. El trabajo de la adolescencia, por tanto, conlleva un proceso de duelo en riesgo, como en el caso expuesto, de devenir melancólico. La posibilidad de que un proceso de duelo frente a la pérdida derive en una melancolía, explica Freud (1915/1986e), depende de la modalidad del vínculo del sujeto al objeto, y a la identificación del propio yo con los elementos repudiados de éste, cuestiones ambas que ponen en juego los envoltorios narcisistas del sujeto. Que el duelo no devenga melancólico, depende entonces, de la apertura del sujeto a la simbolización: a la disparidad que entre el sujeto y el objeto introducen las palabras que permiten la representación de los estados anímicos y de las partes no expresadas de la propia historia. Como ya se ha señalado, en la resolución de las dependencias del adolescente a los apuntalamientos de la infancia, se requiere de manera importante del encuentro con el otro. Este encuentro con la alteridad que representa el semejante, es importante en cuanto moviliza, más allá del solo encuentro intersubjetivo, un espacio de simbolización que propicia la deconstrucción de las posiciones fantasmáticas de la infancia y proyecta la singularización de la propia historia, la que se narra, entonces, en primera persona. Sin embargo, como se puede desprender del caso expuesto, la construcción de este posicionamiento individual frente a la novela y la historia familiar (Douville, 2004), no está desprovisto de superposiciones y de enlaces identificatorios de carácter imaginario, que proyectan modos de fijación a los objetos incestuosos y agresivos de la infancia. Así una madre que no se queja, que guarda un silencio melancólico, se expresa en la demanda no dicha de un hijo que no puede dejar de repetir el desencuentro con un padre ausente, objeto de rechazo e idealización. Frente a estos impedimentos el trabajo de elaboración adolescente se detiene, no logrando reorganizar el trabajo de simbolización según la apertura al tiempo de la metaforización y la subjetivación (Pirard, 2010), es decir, al tiempo simbólico de la disparidad subjetiva que conlleva, dejar de esperar lo que siempre se ha esperado, introduciendo un espacio de discontinuidad frente a una experiencia con el otro, continua y monótona. 


\section{Conclusión}

Del valor asignado a los conceptos de pulsión y objeto hemos destacado la relevancia de los problemas asociados a la noción de subjetivación, que como posibilidad de definición del devenir de las apropiaciones subjetivas, es también la consideración por el lugar que debe ser asignado a la variable intersubjetiva presente en el análisis. Otros tantos aspectos de índole metapsicológica han sido destacados desde la noción de subjetivación, observando su relevancia para posicionarlos de un modo escasamente trabajado. Considerando el encuentro original y (des)alienante que el análisis revierte para un sujeto, la introducción de la variable intersubjetiva se torna central en la comunicación del vivenciar inconsciente, para las formas y modos en que se realiza esa comunicación, permitiendo discriminar la posición del agente de estas comunicaciones y el lugar de quien las recibe en calidad de objeto. La "disparidad subjetiva" que ubica al objeto de la pulsión como otro sujeto, es ya la introducción de la presencia del Otro en el registro trasferencial.

La subjetivación nos trae de este modo la discusión por el lugar del objeto en los procesos de devenir de lo subjetivo, significativamente importante para las reflexiones sobre el curso de la cura psicoanalítica y de la trasferencia. Tomar en cuenta esta dimensión intersubjetiva en la valorización de la pulsión como agente de un sentido mensajero, equivale entonces a volver a puntualizar algunas cuestiones relativas al lugar que los procesos de representación cumplen en la vida psíquica, ya sea en sus extensiones de representaciones de cosa, de palabra o de afecto. Lo importante es visualizar que ellas no adquieren un valor relevante en la sola consideración del plano intra-psíquico, pues poseen un valor relacional e intersubjetivo. La función-sujeto obtenida desde el entendimiento de la pulsión como empuje pre-subjetivo, debe ser también admitida para las formas de encuentro con el otro, pues hacia él van dirigidos los impulsos que los representantes pulsionales actualizan en las diversas figuras de las formaciones inconscientes. Agencias significantes que instituidas desde el Otro, son también maneras que el sujeto posee para reconocerse, sentirse, verse y amarse. La cuestión de la subjetivación nos convoca a una concepción dinámica de la vida anímica, ordenada de acuerdo a un devenir de pasaje entre formas anímicas internas y relacionales. Y donde la vida pulsional, adquiere un resorte único e incontestable. 


\section{ARTIGOS}

\section{Referencias}

Canh, R. (2004) Adolescence et folie, les déliaisons dangereuses. Paris, Fr: PUF.

Cahn, R. (2004). Subjectalité et subjectivation. Adolescence, 50(4), 755-766.

Canguilhem,G. (2002). Études d'histoire et de philosophie des sciences. Paris, Fr: Vrin.

Douville, O. (2004). Fondations subjectives du temps à l'adolescence. Adolescence, 50(4), 767-780.

Freud, S. (1986a). Estudios sobre la histeria (Vol. II). In Obras Completas. Buenos Aires, Ar: Amorrortu. (Trabajo original publicado en 1893-1895).

Freud, S. (1986b). Sobre la justificación de separar de la neurastenia un determinado síndrome en calidad de neurosis de angustia (Vol. III). In Obras Completas. Buenos Aires, Ar: Amorrortu. (Trabajo original publicado en 1895[1894]).

Freud, S. (1986c), Manuscrito K. Las neurosis de defensa. Un cuanto de navidad (Vol. I). In Obras Completas. Buenos Aires, Ar: Amorrortu. (Trabajo original publicado en 1896).

Freud, S. (1986d). Pulsiones y destinos de pulsión (Vol. XIV). In Obras Completas. Buenos Aires, Ar: Amorrortu. (Trabajo original publicado en 1915).

Freud, S. (1986e). La represión (Vol. XIV). In Obras Completas. Buenos Aires, Ar: Amorrortu. (Trabajo original publicado en 1915).

Freud, S. (1986f). Psicología de las masas y análisis del yo (Vol. XVIII). In Obras Completas. Buenos Aires, Ar: Amorrortu. (Trabajo original publicado en 1921).

Freud, S. (1986g). Proyecto de psicología para neurólogos (Vol. I). In Obras Completas. Buenos Aires, Ar: Amorrortu. (Trabajo original publicado en $1950[1895])$.

Green, A. (2015). Le discours vivant, Paris, Fr: PUF.

Lacan, J. (1991). Le séminaire. Livre VIII. Le transfert. Paris, Fr: Seuil. (Trabajo original publicado en 1960-1961).

Lacan, J. (1992). Le seminaire. Livre 11. Les quatre concepts fondamentaux de la psychanalyse. Paris, Fr: Seuil. (Trabajo original publicado en 1964).

Lauru, D. (2016). Lacan à l'adolescence. Adolescence, t. 34 2(2), 357-376.

Leclaire, S. (1975). On tue un enfant. Paris, Fr: Seuil.

Le Poulichet, S. (2004). Les devenirs-sujet. Adolescence, 50(4), 781-788.

Pirard, R. (2010). L'enveloppe de l'objet sur le rapports entre symptôme et jouissance. In Le sujet postmoderne entre sympôme et jouissance. Toulouse, Fr: Érès. 
Pirard, R. (2013). L'époque et le sujet. Psychanalyse, 26(1), 101-121.

Roussillon, R. (2012). Agonie, clivage et symbolisation. Paris, Fr: PUF.

Richard, F. (2001). Le processus de subjectivation à l'adolescence. Paris, Fr: Dunod.

\section{Resumos}

(Em torno da noção de subjetivação em psicanálise: entre a dinâmica pulsional, identificação e objeto)

$O$ artigo faz uma análise cuidadosa sobre o conceito de subjetivação em psicanálise, evidenciando a relevância que essa categoria adquire para compreender o caráter psíquico e relacional das dinâmicas pulsionais supostas pela teoria psicanalítica. Sem ser uma categoria de análise trabalhada diretamente por Freud em seus estudos clínicos ou metapsicológicos, a subjetivação pode atuar como uma hipótese derivada do trabalho historizante que as pulsões inconscientes cumprem no devir da vida psíquica. Junto com especificar o vínculo que guardam noções, como sujeito, pulsão, identificação, objeto e transferência, a subjetivação permite compreender de melhor maneira a ação clínica realizada pelo exercício do psicanalista. O caráter psíquico e relacional posto em jogo pela noção de subjetivação é finalmente ilustrado por meio de um caso clínico.

Palavras-chave: Psicanálise, metapsicologia, pulsão, identificação, objeto

(About the notion of subjectivation in psychoanalysis: Between drive dynamic, identification and object)

This article offers a detailed analysis of the concept of subjectivation in psychoanalysis and highlights the importance of this category to understand the psychic and relational characters of the drive dynamics assumed by the psychoanalytic theory. Despite the fact that Freud did not work directly on this analysis category in his clinical and metapsychological studies, subjectivation may act as a hypothesis derived from the historizing impact unconscious drives have on the development of psychic life. In addition to identify the relationships between subject, drive, identification, objects and transference, subjectivation provides a better understanding of the clinical performance of psychoanalysts. To conclude, the psychic and relational nature brought into play by subjectivation is illustrated by a clinical case.

Key words: Psychoanalysis, metapsychology, drive, identification, objec 


\section{ARTIGOS}

(Autour de la notion de subjectivation en psychanalyse: entre dynamique pulsionnelle, identification et objet)

Cet article propose une analyse détaillée du concept de subjectivation en psychanalyse, mettant en évidence la pertinence que cette catégorie acquiert pour comprendre le caractère psychique et relationnel des dynamiques pulsionnelles supposées par la théorie psychanalytique. Sans être une catégorie d'analyse travaillée directement par Freud dans ses études cliniques ou métapsychologiques, la subjectivation peut servir d'hypothèse dérivée du travail historique que les pulsions inconscientes accomplissent dans l'avenir de la vie psychique. En précisant le lien que gardent des notions telles que sujet, pulsion, identification, objet et transfert, la subjectivation permet de mieux comprendre l'action clinique réalisée par le psychanalyste. Le caractère psychique et relationnel mis en jeu par la notion de subjectivation est enfin illustré par un cas clinique.

Mots clés: Psychanalyse, métapsychologie, pulsion, identification, objet

Citação/Citation: Bilbao, A., \& Jofré, D. (2020, março). En torno de la noción de subjetivación en psicoanálisis: entre dinámica pulsional, identificación y objeto. Revista Latinoamericana de Psicopatologia Fundamental, 23(1), 17-36. http://dx.doi.org/10.1590/ 1415-4714.2020v23n1p17.3.

Editora/Editor: Profa. Dra. Sonia Leite

Submetido/Submitted: 13.10.2019/ 10.13.2019 Aceito/Acepted: 21.11.2019/11.21.2019 
Copyright: (C) 2009 Associação Universitária de Pesquisa em Psicopatologia Fundamental/ University Association for Research in Fundamental Psychopathology. Este é um artigo de livre acesso, que permite uso irrestrito, distribuição e reprodução em qualquer meio, desde que o autor e a fonte sejam citados / This is an open-access article, which permits unrestricted use, distribution, and reproduction in any medium, provided the original authors and sources are credited.

Financiamento/Funding: Este trabalho recebeu apoio del Governo do Chile: "Centro de Estudios interculturales e indígenas", n. 151100006. / This work is supported by Governo do Chile: "Centro de Estudios interculturales e indígenas", n. 151100006.

Conflito de interesses/Conflict of interest: Os autores declaram que não há conflito de interesses. / The authors declare that there is no conflict of interest.

\section{Alejandro Bilbao}

Instituto de Neurociencias Clínicas, Facultad de Medicina, Universidad Austral de Chile; Investigador Asociado FONDAP (151100006).

Facultad de Medicina - Campus Isla Teja

Casilla 567

Valdivia, Chile

manuel.bilbao@uach.cl

https://orcid.org/0000-0002-8064-0694

\section{DANiel Jofré}

Instituto de Psicología; Universidad Austral de Chile (Puerto Montt, Chile); Investigador Asociado FONDAP (151100006)

Universidad Austral de Chile - Sede Puerto Montt

Casilla 1327

Puerto Montt, Chile

daniel.jofre@uach.cl

https://orcid.org/0000-0002-7902-4704

This is an open-access article, which permits unrestricted use, distribution, 